\section{From $C M \mathcal{F}$ to $C M A \mathcal{F}$}

CMA7 breaks a 6-year tradition with its new editorial fellow. Dr. Aleksandra (Sa ̌sa) Mišsak is the first fellow from abroad and the first with substantial editorial experience.

MiŠsak has been a manuscript editor at the Croatian Medical fournal in Zagreb, Croatia, since 2000. The English-language general medical journal is the country's largest, printing 2000 copies every second month.

The melding of medicine and language is ideal for Mišsak, $\sim$ who is pursuing a doctorate in $\mp$ language communication and cognitive neuroscience. "I thought it would be impossible to combine the two," she says.

CMF co-editor Dr. Ana Marusic recommended Mišak for the year-long $C M A 7$ editor- ial fellowship, "so we can increase the quality of what we do," says Miß̧ak.

As a resident of a former Communist country that only recently emerged from war (1991-1995), Mi ̌̌sak also brings a unique perspective to the journal.

So far, she says the pace at $C M A 7$ is more intense than home as she takes on new challenges, such as manuscript assessment. She's also been charged with looking after the Holiday Review issue. "Sometimes there's a thin line between being brave and being crazy. I'm hoping for the best," she laughs.

The fellow, who acts as an associate scientific editor, spends a year reviewing submissions, corresponding with authors and working closely with the senior

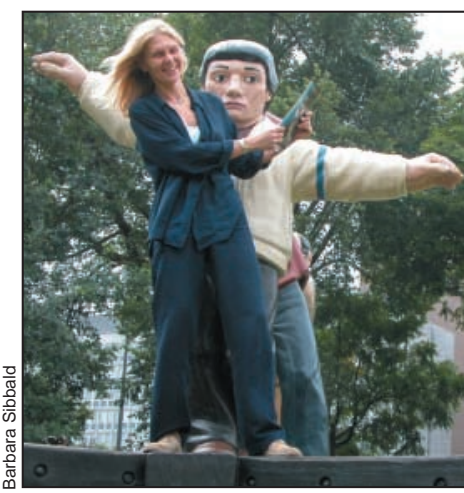

Mišak: A balancing act between cultures and languages.

editorial team to develop clinical and editorial content.

Applications for the 2005 editorial fellowship must be received by Dec. 15, 2004 (www.cmaj .ca/misc/fellowship.shtml). Barbara Sibbald, CMAJ

\title{
New Technology
}

\section{Telemedicine: On, under and out of this world}

New Canadian telemedicine technology being tested in an $\sim$ underwater laboratory off the F coast of Key Largo in Florida - could be used to deliver emergency diagnostic and surgical care to astronauts in space $\stackrel{\circ}{\circ}$ and to patients in remote areas on Earth.

○ On Oct. 11, North Bay sur-

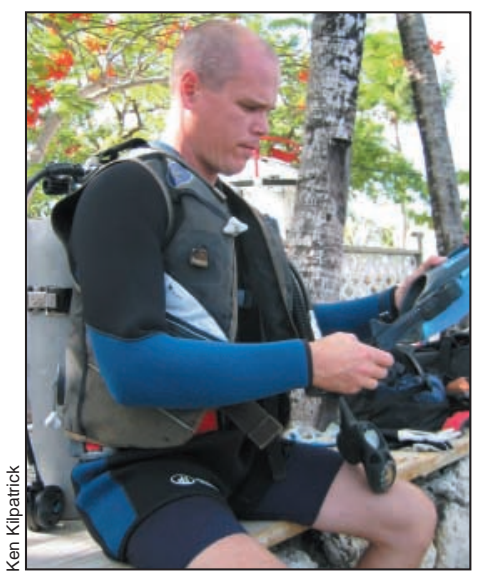

Over the moon: Mission member Dr. Craig McKinley hopes to become an astronaut. geon Dr. Craig McKinley and 3 astronauts-turned-aquanauts will enter the $3 \times 14$-metre underwater chamber Aquarius for a 10day mission called NEEMO 7. Their main task will be to test remote surgical simulations.

Three Canadian physicians are on the mission: McKinley, Mission Commander Dave Williams and Chief Scientist Mehran Anvari. Much of the technology being tested was developed at McMaster University's Centre for Minimal Access Surgery in Hamilton, Ont.

NEEMO 7 "will have a major impact on current research and development of new technologies, including new robotic and surgical platforms that can be used on earth and beyond," says Anvari, head of the McMaster Centre.

"The centre did some work last year with NASA, looking at all aspects of surgery," Anvari explains. "We came to the conclusion that robotic surgery is going to be the answer because of limitations of humans in a zero gravity environment.

"Laparoscopic surgery is the preferred way because the blood and other bodily fluids are confined. ... However, when a surgeon operates in zero gravity, he or she tends to exert more pressure at the tip of the instruments whereas if robots are naturally fixed, there is no pressure difference at zero gravity."

Both telementoring (allowing Anvari to watch and advise) and telerobotics (allowing Anvari to clinically intervene in operations) will be tested aboard Aquarius. Aquarius crewmembers will participate in several mock procedures including ultrasound diagnosis, ultrasound drainage of an abscess, suturing of vessels and nerves and performing a stone extraction.

McKinley was clearly over the moon about the opportunity. "I wanted to be an astronaut when I grew up," he says. - Ken Kilpatrick, Hamilton, Ont. 